\title{
The Effectiveness of Product Placement in Music Videos: A Study on the Promotion Strategies for Brands and Products to Target the Y Generation in Johannesburg
}

\author{
Lameez Omarjee
}

\author{
Norman Chiliya \\ School of Economics and Business, University of Witwatersrand \\ Private Bag 3, Wits, 2050, South Africa \\ Email: Norman.chiliya@wits.ac.za
}

Doi:10.5901/mjss.2014.v5n20p2095

\begin{abstract}
Product placements are strategic brand placements within media that are meant to be noticed by the consumer, to further influence purchase intentions. Placements in music videos have grown in recent years however, there is little research on placements in this medium and available research has not measured the influence of product placement on purchase intention. The study addressed the gap where product placement in music videos was under researched. This paper investigated the effectiveness of brands and products placements in music videos in influencing the purchase intentions of the $Y$ generation population living in Johannesburg. A self-administered research questionnaire was used to collect data through a quantitative research method by convenience sampling of 420 randomly chosen respondents, aged between 18-27, obtained from the University of the Witwatersrand and Johannesburg. A six minute music video stimulus was used for respondents to base their opinions about placements. The results indicate reliability of the constructs in the model developed as Cronbach Alphas were greater than 0.6 for the variables. The main findings show the variables individual factors and execution stimulus are significantly related to brand recall, brand recognition and brand choice. In turn, brand recall, brand recognition and brand choice influence the consumer's purchase intentions. The strongest linear relationship existed between brand choice and purchase intention. Placement strategies are equally effective for consumers in the $Y$ generation of differing genders, income brackers and age groups. The research reveals that music videos are an effective platform to reach the targeted $Y$ generation population and the model adapted for placements in music videos shows the stages of the processing in the consumer's mind from exposure to placements to the final purchase intention. The findings contribute to the knowledge of strategies marketers should use to promote brands and products to effectively target the South African Y generation.
\end{abstract}

\section{Introduction to the Research}

Marketers are constantly finding and developing ways to target consumers accurately and successfully. Due to the rise of the postmodern consumer (Gordon \& Valentine, 2000) and increased media fragmentation due to the development of technology communication devices (Van der Waldt, Du Preez, Williams, 2008a) traditional mass media advertising has come under criticism for being limited in being effective as the strategy is not versatile (Percy, 2006).

Marketers have shown a growing interest in non-traditional media advertising strategies (Balasubramanian, Karrh \& Patwardhan, 2006). Product placement is one of these new marketing strategies that seek to address the limitations of traditional mass media advertising (Percy, 2006). Product placements are strategic brand placements within a medium to be noticed by the consumer (Gupta \& Lord, 1998). Marketers have been in search of new venues to place products to gain reach and target potential consumers better (Van der Waldt, Nunes \& Stroebel, 2008b).

Placements in music videos have grown particularly in the pop, rap and $\mathrm{RnB}$ genre. The $\mathrm{Y}$ generation particularly listens to this music and watches music videos and subsequently marketers have found that music videos are a useful medium to target adolescent audiences (Schemer et al., 2008). The launch of YouTube eight years ago (2005) (Cheng, Dale \& Liu, 2007) and the development of smartphones with fast internet connections mean that access to music videos would no longer be limited to MTV or Vh1 on television (Plambeck, 2010).

Music videos are a lucrative medium for marketers to use to communicate brands to target consumers. Published news articles like the New York Times have studied this trend in music, but not in depth, there is still room to investigate its potential effectiveness in influencing consumer purchase intentions. 


\section{Problem Statement}

For this research, the placement of brands was investigated, in the context of South African markets, where the target is the Y generation; those consumers born between 1982 to 2000 (Schiffman \& Kanuk, 2009) particularly those consumers who grew up in the 90's and are now entering the work place (Saunders, 2011) or completing tertiary education as these consumers have obtained increased purchasing power (Nuttall, 2004).

The $Y$ generation is a profitable market to consider and companies like Microsoft have directed recent promotional campaigns to target the $Y$ generation to promote Internet Explorer 10 (Windows 8) (Microsoft South Africa, 2013). This research is specific to the $Y$ generation in South Africa, because this is a very diverse group of individuals, who may have backgrounds at opposite ends of a spectrum.

Previous South African studies on product placements are limited to mediums like film and broadcast programs, not music videos and investigated the recognition and recall of placed products (Van der Waldt et al., 2008a). The magnitude of that impact of product placements should be measured in terms of its ability to motivate consumer purchase intentions (Van der Waldt et al., 2008b). Available research has not explored the influence of product placements on purchase intention (Schemer et al., 2008). The purchase intention of consumers following exposure to a placement must be determined (Van der Waldt, et al., 2008a).

Research on the effectiveness of product placements in music videos is rare; there are mostly articles on blogs and websites to support available research (Karbasfrooshan, 2011). A study by Lee, Sung and de Gregorio (2011) identified that a future research area for placement strategies was to investigate music as a medium and to determine the effectiveness of such a strategy, given that consumers have neutral or uncertain attitudes towards placements in music because the practice is fairly new.

This research will assess the general attitude to product placements by investigating if unsuspecting generation $Y$ consumers notice the brands and products the consumers are being exposed to in music videos.

\section{Research Objectives}

This section will explain the primary and secondary research objectives.

\subsection{Primary Objective}

The primary objective of the study was to determine if product placement in music videos is an effective strategy in influencing the final purchasing intentions of viewers or consumers of the placed products or brands.

The outcomes and conclusions drawn should contribute to the knowledge and improvements about marketing strategies for brands and products to appropriately target the South African $Y$ generation.

\subsection{Secondary Objectives}

The following objectives were needed to accomplish the primary aim of the research.

a. To create a model to be tested showing that exposure to product and brand placement in music videos creates brand awareness (recall, recognition and choice) and will eventually influence purchase intention accordingly.

b. To collect data from a sample population by conducting a survey that tests the model and then analyzing the observations and results.

c. To conclude if product placement, particularly in music videos, is a viable component of integrated marketing communications to use as a promotion strategy for marketers to target the South African $\mathrm{Y}$ generation and make recommendations based on these findings.

\section{Literature Overview}

This section is a brief overview of the literature and models used to make deductions and draw secondary research conclusions for the model to be developed for this study.

\subsection{Product Placement}

Product placement is not a new phenomenon. The strategy was introduced in the 1930's and has since grown in 
credibility as a marketing strategy (Gupta \& Lord, 1998). Product placement is the paid or purposeful inclusion of a brand or a particular product of a brand in mass media (Balsubramanian, Karrh \& Patwardhan, 2006).

Placements differ to traditional classical advertising as placements are more hidden or subtle in nature (Schemer et al., 2008) this means the strategy is less advertorial (Neer, 2003). Sometimes the placement is unintentional and unpaid, voluntary or involuntary (Schemer et al., 2008). Usually a marketing agency will negotiate on behalf of a company or brand (the client) to have the brand or product representing the brand placed in a medium such as a movie, book, video game, song, magazine or television series (Neer, 2003).

Available research on the marketing strategy has investigated the role and effectiveness of placements in mediums like movies (Balasubramanian, Gupta \& Klassen, 2000) and television series (Russell, 2002). Published articles show studies on factors that determine effectiveness of program-integrated advertising such as the context and plot of a movie or television series, the characters and the association between the brand and the character (Schemer et al., 2008), including the modality (mode of communication whether visual-only, audio-only and audio-visual) and how these factors influence consumer behaviour or brand awareness amongst viewers (Karrh, McKee \& Pardun, 2003). The context in which the placement is shown influences the reaction of consumers (Gupta \& Gould, 1997). The persuasiveness of placements is measured by considering memory and attitude effects as recall alone is a poor indicator of the effectiveness of a placement (Russell, 2002).

The study on the effectiveness of placements in movies by Gupta and Lord (1998) indicates that prominent placements lead to higher recall than subtle placements of products. A placement is classified as prominent when the brand identifier is visible due to size, and the centrality of the position on the screen. A placement is classified as subtle when the brand identifier is small in size, in the background, used as a prop, displayed amongst other products and has low screen time exposure (Gupta \& Lord, 1998).

Product placements should not be explicitly noticeable, consumers should not feel as though there is a commercial within a program, the placement must not be obviously intrusive on the consumer's viewing (Neer, 2003). If placements seem pretentious the placement may be perceived negatively (Gardiner, 2006). Product placements are considered more effective than traditional adverts if placements do not come across as persuasive, commercial messages (Russell, 2002).

Good placements constitute products or brands that have presence in the scene, but must not be the central focus of the scene, the products should fit seamlessly into the scene given the context. The placement is successful if brand awareness is promoted (Neer, 2003). Placements of real brands and products are often used to create realism about the story; for example, part of the wardrobe of the cast or characters in the music video, without having the company being approached for the use of a brand or product (Neer, 2003).

Studies on the mode of placement indicate the explicit mentioning of a placement in audio script without any visual display results in higher recall of the brand as opposed to a subtle, visual-only depiction. Although, adding audio enhancements to a prominent visual display does not guarantee the enhanced brand recall (Gupta \& Lord, 1998). Audiovisual placements are the best combination of modes to use in a placement strategy, although these placements are difficult to accommodate and are the most expensive option for marketers.

Subtle placements are easier to integrate and are less costly than prominent placements, but marketers must make a decision to trade-off cost with consumer brand recall (Gupta \& Lord, 1998).

Sometimes arrangements are made with the company in question, there can be an agreement to exchange the appearance of the brand provided that the company provides cast and crew with the product, sometimes as refreshments throughout the shoot, and sometimes money is also a good compensation alternative. Musical artists promote products in music videos and get paid for the placements (Neer, 2003), the money received often covers costs for promoting the album (Plambeck, 2010). The expenses incurred are worthwhile as the product placements appear effective (Gupta \& Gould, 1997).

Marketers and companies are willing to pay for placements due to the boost in sales of the brand and product that follows (Neer, 2003). This can be seen in the example where sales of the Cognac Courvoisier increased by $20 \%$ after the song "pass the Courvoisier" sung by Busta Rhymes and PDiddy was released, although no agreement was made for the placement between the Cognac brand and the artists (Schemer et al., 2008).

\subsection{Theories and Models of Product Placement}

The model on which the research of this study was based is adapted from Balasubramanian, Karrh \& Patwardhan (2006) for music videos as the medium for the placement within a South African context. 
Figure 1. Audience Response to Product Placement

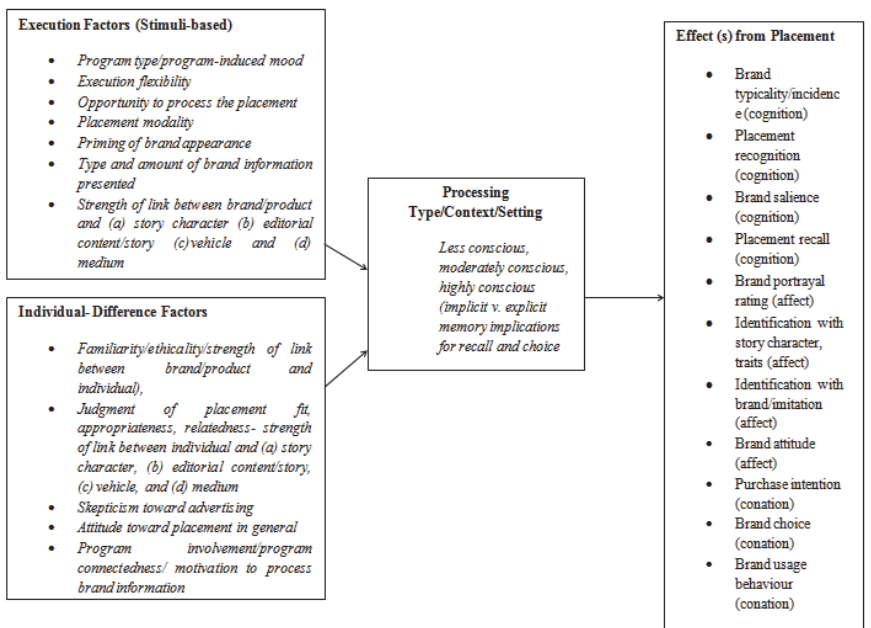

Source: Balasubramanian, Karrh \& Patwardhan (2006)

The four main components are the execution and individual level variables followed by the depth of placement processing, these are the independent variables and the outcomes and placement effects are the dependent variables (Balasubramanian et al., 2006).

\subsection{Proposed Theoretical Model and Hypotheses}

The model sourced in Balasubramanian, Karrh \& Patwardhan (2006) was adapted to test the outcomes of product placement in music videos relative to targeting the South African Y generation (aged 18-31).

This model shows that there are three main relationships; the independent variables influence the dependent variables which lead to the outcome. The independent variables are the execution stimulus and the individual factors, which are comprised of components (Lawson-Body \& Limayem, 2004) that serve to influence dependent variables, the processing in memory, comprised of components being (explicit) brand recall and recognition and (implicit) brand choice. These dependent variables in turn influence the outcomes, which is the purchase intention of the consumer.

Model of Audience Response to Product Placements in Music Videos

Independent Variables

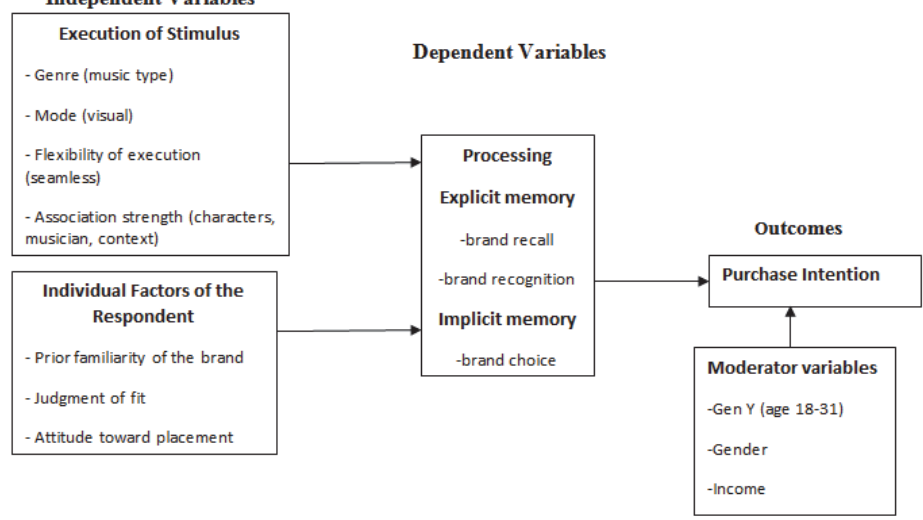

- $\mathrm{H}_{1}$ : There is a relationship between the execution of a stimulus (independent variable), and brand recall (dependent variable). 
- $\quad \mathrm{H}_{2}$ : There is a relationship between the execution of a stimulus (independent variable), and brand recognition (dependent variable).

- $\mathrm{H}_{3}$ : There is a relationship between the execution of a stimulus (independent variable), and brand choice (dependent variable).

- $\quad \mathrm{H}_{4}$ : There is a relationship between the individual factors (independent variable), and brand recall (dependent variable).

- $\mathrm{H}_{5}$ : There is a relationship between the individual factors (independent variable), and brand recognition (dependent variable).

- $\quad \mathrm{H}_{6}$ : There is a relationship between the individual factors (independent variable), and brand choice (dependent variable).

- $\mathrm{H}_{7}$ : There is a relationship between brand recall and purchase intention.

- $\mathrm{H}_{8}$ : There is a relationship between brand recognition and purchase intention.

- $\quad \mathrm{H}_{9}$ : There is a relationship between brand choice and purchase intention.

- $\mathrm{H}_{10}$ : There is a difference in responses of people of differing age, gender and income in relation to purchase intention.

- $\mathrm{H}_{10 \mathrm{a}}$ : There is a difference in responses of men and women in relation to purchase intention, after being exposed to product placement in music videos.

- $H_{10 b}$ : There is a difference in responses of consumers of differing age in relation to purchase intention, after being exposed to product placement in music videos.

- $\mathrm{H}_{100}$ : There is a difference in responses of consumers of differing income brackets in relation to purchase intention, after being exposed to product placement in music videos.

\section{Methodology}

\subsection{The Sample}

A sample constructed of consumers were randomly chosen to fairly represent the $Y$ generation in South Africa, with an average age group between the ages of 18-31. The sample was easily obtainable from the Johannesburg, Witwatersrand University area. Johannesburg was chosen as a geographical base as most people move to big cities to pursue tertiary education and job opportunities.

The potential respondents do not only represent the Johannesburg population of the country but is a fair representation of people who come from all of the nine provinces in the country and neighboring African countries and is thus representative of the population, without personal bias in selection (Galpin \& Krommenhoek, 2013).

The university was selected as the targeted consumers were conveniently accessible through the institution. The university is one of Africa's leading universities; the university is a common place for students from different social, economic, demographic and psychographic backgrounds to assemble. This means the reliable and valid reach for the research was obtained to ensure fair and random results.

Using Raosoft sample size calculator, a single sample size was estimated to be 377 people. A total of 450 people were contacted to make provision for any data that may have become lost or was recorded inaccurately. The 450 people selected were suitable for the time and cost constraints. Discrete data was used to draw a random sample. The stratified sampling method was used; the student population was divided according to faculties and the students were randomly selected from the faculties, to give everyone in the student population a fair and equal chance of being selected (Galpin \& Krommenhoek, 2013).

\subsection{Research Design}

The research was descriptive because of the aim to be conclusive of the market characteristics and functions, the single cross-sectional design allowed for responses to be drawn from a single sample at least once (Malhotra, 2009).

The quantitative research analysis method was useful in examining concepts and variables of interest developed in the literature review, on which the hypotheses were based. Quantitative methods made it possible to generalize the results beyond the sample and to apply results to the population, making findings representative (Galpin \& Krommenhoek, 2013). The methods employed involved the use of surveys which allowed for individual focus on respondents as discrete objects of inquiry (Malhotra, 2009). 


\subsection{Data Gathering}

To obtain quantitative data, surveys were conducted. Questionnaires were distributed to the sample to obtain responses for the study. The formal questionnaire consisted of questions in a prearranged order (a structured method). Comprehensive questions were asked about the consumer behaviour, attitudes, and awareness of products and brands, as well as demographic and lifestyle characteristics to ensure thorough conclusions of purchase intention could be determined. The survey method was selected as this method was simple and easy to administer questionnaires. Survey methods ensured that responses were reliable and the coding, analysis and interpretation of data was simple and manageable (Malhotra, 2009)

The questionnaire took approximately 15 to 20 minutes to complete. Questionnaires were distributed physically by the researcher to students on the different campuses, in computer labs where access to YouTube was available for the viewing of the music video. Once all questionnaires were returned, the researcher confirmed that questions were answered accurately and that there were no omissions to ensure questionnaires were valid for use in the data processing. Any questionnaires with discrepancies; were discarded. At the end of the process, of the 450 questionnaires distributed, 420 questionnaires were usable for analysis.

\subsection{Data Analysis}

The statistical software SAS Enterprise Guide 5.1 was used to perform the various statistical analyses. Responses of the questionnaire were coded and entered onto a Microsoft Excel spread sheet. Dependent variables tested were the brand recall, brand recognition, brand choice and purchase intention. The individual factors of the respondent and the execution stimuli were independent variables. Cronbach Alpha coefficients were calculated to test for the reliability of constructs and a factor analysis was conducted to test for validity. ANOVA tests were conducted to determine relationships of the observations with moderator variables (age, gender, income, behaviour) and further linear regression analysis was performed to test the proposed hypotheses.

\section{Inferential Statistics}

\subsection{Factor Analysis}

To check for validity in the results, a factor analysis was run on the Varimax Rotation method using the SAS Enterprise Guide

\subsection{Varimax Rotation}

The Varimax Rotation of the analysis shows that the rotations for purchase intention and brand choice could not be conducted. The table shows that for brand recall the highest loadings are under factor 1 and the variance explained by the factor was 2.3691401, compared to the variance explained by factor 2 which was less; 1.9765742 . The highest loadings for brand recognition loaded under factor 1 and the variance explained by the factor was 2.2706230, variance explained by factor 2 was less; 1.6227486. For the execution stimulus, the highest loadings were under factor 1 and variance explained was 2.8679705, variance explained by factor 2 was 2.1052237.

Table 1: Varimax Rotated Factor Pattern

\begin{tabular}{|l|c|c|}
\hline Factor Pattern & Factor 1 & Factor 2 \\
\hline & 0.67627 & 0.38792 \\
\hline Brand Recall- The consumer can recall some of the brands and products in the music video. & 0.76024 & 0.27081 \\
\hline Brand Recall- The consumer can remember the location of the placements. & 0.81400 & 0.16994 \\
\hline Brand Recall- The consumer can remember how he or she felt when he or she saw the placements. & 0.20203 & 0.80242 \\
\hline Brand Recall- The consumer was too distracted to pay attention to the visuals. & 0.25795 & 0.64745 \\
\hline Brand Recall- The consumer will not remember the brands and products at a later stage. & 0.10083 & 0.81057 \\
\hline Brand Recall- The consumer feels brands and products were displayed for short periods of time. & 0.74412 & 0.06141 \\
\hline Brand Recall- The placements have improved the consumer's awareness of the brands \& products. & 0.97415 & -0.05401 \\
\hline Brand Recognition- The consumer did not notice any brands or products in the music video. & & \\
\hline
\end{tabular}




\begin{tabular}{|l|c|c|}
\hline Brand Recognition- The consumer did not recognize any brands or products in the music video. & -0.97415 & 0.05401 \\
\hline Brand Recognition- The consumer thinks the brands and products in the music video are well known. & 0.59381 & 0.39006 \\
\hline Brand Recognition- The consumer thinks the brands and products in the music video are overwhelming. & -0.06751 & 0.63163 \\
\hline Brand Recognition- The brands and products in the music video remind the consumer of commercials. & 0.05409 & 0.74501 \\
\hline Brand Recognition- The consumer uses some of the brands and products in the music video. & 0.11220 & 0.71468 \\
\hline Execution Stimulus- The Products and Brands were Placed in the Correct Context & 0.77833 & 0.03908 \\
\hline Execution Stimulus- The Products and Brands Match the Image of the Artist & 0.76906 & 0.07600 \\
\hline Execution Stimulus- The Products and Brands were Used in the Music Video & 0.71545 & 0.33002 \\
\hline Execution Stimulus- The Products and Brands were Well-Integrated in the Music Video & 0.57466 & 0.45682 \\
\hline Execution Stimulus- The use of Products and Brands was Demonstrated in the Music Video & 0.56682 & 0.51196 \\
\hline Execution Stimulus- The Consumer is Familiar with the Products and Brands used in the Music Video & 0.33762 & 0.61886 \\
\hline Execution Stimulus- The Products and Brands in the Music Video were Visible & 0.41209 & 0.54654 \\
\hline Execution Stimulus- The Products and Brands in the Music Video were Central to the Focus of the Screen & 0.40035 & 0.51256 \\
\hline Execution Stimulus- The Consumer would have noticed the Products and Brands if they were Mentioned & 0.25148 & -0.75750 \\
\hline
\end{tabular}

The reliability of the results (consistency in results if measurements are taken repeatedly) was measured using the Cronbach's Alpha calculation. A score greater than 0.6 indicates satisfactory reliability and the greater the score the more reliable the result (Malhotra, 2009).

The analyses were run using the SAS Enterprise Guide for the responses of the 420 respondents. Below the results of the Cronbach Alpha coefficients for each of the constructs will be indicated.

\subsection{Cronbach Alpha}

\subsubsection{Purchase Intention}

The reliability of the construct purchase intention was measured on five variables, each on a Likert scale. The results of the full research survey indicate a Cronbach Alpha measurement of 0.9153 . The results show there is reliability as the Cronbach Alpha measurements are far greater than 0.6 and close to 1 . The Cronbach Alpha score for purchase intention in the pilot study was 0.901283 , in the final completed study that value improved slightly to 0.915339 . This shows variables are highly (excellently) correlated with each other and there is internal consistency. The table below shows the Cronbach Alpha scores for the constructs.

Table 2: Cronbach Alpha Scores for Purchase Intention

\begin{tabular}{|l|l|}
\hline \multicolumn{2}{|l|}{ Cronbach Coefficient Alpha } \\
\hline Total & 0.915339 \\
\hline Cronbach Coefficient Alpha with Deleted Variables & 0.910810 \\
\hline Consider Buying the Products and brands in the Music Video & 0.901747 \\
\hline Search for Information on the Products and the Brands in the Music Video & 0.882989 \\
\hline Look for the Products and Brands in the Music Video at Local Stores & 0.883895 \\
\hline Inquire about the Products and Brands in the Music Video at Local Stores & 0.901039 \\
\hline Plans to Buy the Products and Brands in the Music Video in the Near or Distant Future &
\end{tabular}

\subsubsection{Brand Choice}

Brand choice was measured on a Likert scale with five variables. The results of the full research survey indicate a Cronbach Alpha of 0.8418 . The results show there is reliability as the Cronbach Alpha measurements are greater than 0.6. The Cronbach Alpha score for brand choice in the pilot study was 0.910178 , this is fairly higher than the Cronbach Alpha score of the final study, 0.841809 . Nevertheless, the variables are still highly correlated and there is internal consistency. The table below shows the Cronbach Alpha scores for the constructs. 
Table 3: Cronbach Alpha Scores for Brand Choice

\begin{tabular}{|l|l|}
\hline Cronbach Coefficient Alpha \\
\hline Total & 0.841809 \\
\hline Cronbach Coefficient Alpha with Deleted Variables & 0.836322 \\
\hline The Consumer thinks the Brands and Products in the Music Video are Acceptable & 0.792372 \\
\hline The Consumer would Choose the Products and Brands in the Music Video for himself/herself & 0.827815 \\
\hline The Consumer thinks the Brands and Products in the Music Video are Appropriate & 0.779450 \\
\hline The Consumer would Choose the Products and Brands for his/her Friends and Family & 0.808675 \\
\hline The Consumer Trusts the Brands and Products in the Music Video &
\end{tabular}

\subsubsection{Brand Recall}

Brand recall was measured on a Likert scale with seven variables. The results of the full research survey indicate a Cronbach Alpha of 0.805318 . The results show there is reliability as the Cronbach Alpha measurements are greater than 0.6 .

The Cronbach Alpha score for brand recall in the pilot study was 0.861530 ; this is higher than the Cronbach Alpha score of the final study, 0.805318 . Nevertheless, the variables are still highly correlated and there is internal consistency. The table below shows the Cronbach Alpha scores for the constructs.

\section{Table 4: Cronbach Alpha Scores for Brand Recall}

\begin{tabular}{|l|c|}
\hline Cronbach Coefficient Alpha & 0.805318 \\
\hline Total & \multicolumn{2}{|l|}{} \\
\hline Cronbach Coefficient Alpha with Deleted Variables & 0.762918 \\
\hline The Consumer can Recall some of the Brands and Products Used in the Music Video. & 0.770335 \\
\hline The Consumer Remembers his/her feelings after Exposure to the Placements. & 0.793904 \\
\hline The Placements were Displayed for too Short Periods of Time for Consumers to Recall the Brands and Products. & 0.780187 \\
\hline The Consumer was too Distracted by the Sound of the Music to pay Attention to the Visuals. & 0.790583 \\
\hline The Consumer will not be Able to Remember the Placements at a Later Stage. & 0.793361 \\
\hline The Placements have Improved Consumer Brand Awareness. & 0.766264 \\
\hline The Consumer can Remember the Location of the Placements. & \\
\hline
\end{tabular}

\subsubsection{Brand Recognition}

Brand recognition was measured on a Likert scale with six variables. The results of the full research survey indicate a Cronbach Alpha of 0.615423 . The results show there is reliability as the Cronbach Alpha measurements are greater than 0.6. The Cronbach Alpha score for brand recognition in the pilot study was 0.654702 ; this is higher than the Cronbach Alpha score of the final study, 0.615423 . The variables are still highly correlated and there is internal consistency. The table below shows the Cronbach Alpha scores for the constructs.

Table 5: Cronbach Alpha Scores for Brand Recognition

\begin{tabular}{|c|c|}
\hline \multicolumn{2}{|l|}{ Cronbach Coefficient Alpha } \\
\hline Total & 0.615423 \\
\hline \multicolumn{2}{|l|}{ Cronbach Coefficient Alpha with Deleted Variables } \\
\hline The Consumer did not Notice the Brands and Products in & 0.554426 \\
\hline umer did not Recognize the Brands and Products in the Music Video. & 0.531744 \\
\hline The Use of Brands and Products in the Music Video was Overwhelming. & 0.646075 \\
\hline The Brands and Products in the Music Video Remind the Consumer of Comr & 0.597014 \\
\hline The Consumer Uses some of the Brands and Products in the Music Video. & 0.575578 \\
\hline The Brands and Products used in the Music Video are Well Known. & 0.505223 \\
\hline
\end{tabular}




\subsubsection{Execution Stimulus}

The construct, execution stimulus was measured on a Likert scale with nine variables. The Cronbach Alpha scores for each of the constructs were calculated and show that the results of the full research survey indicate a Cronbach Alpha of 0.7788. The results show there is reliability as the Cronbach Alpha measurements are greater than 0.6.

Cronbach Alpha scores for the execution stimulus conducted in the pilot study were 0.806966 . The Cronbach Alpha score in the final study was slightly less, 0.7788 . The variables show good internal consistency.

The construct, individual factors was measured in separate dimensions such as realism, acceptance, attention or influence and attitude. The table below shows the Cronbach Alpha scores for the constructs.

Table 6: Cronbach Alpha Scores for Execution Stimulus

\begin{tabular}{|l|l|}
\hline Cronbach Coefficient Alpha \\
\hline Total & 0.778854 \\
\hline Cronbach Coefficient Alpha with Deleted Variables \\
\hline The Products and Brands in the Music Video were Visible & 0.749642 \\
\hline The Products and Brands in the Music Video were Central to the Focus of the Screen & 0.754181 \\
\hline The Products and Brands were Well-Integrated in the Music Video & 0.735722 \\
\hline The Products and Brands were Used in the Music Video & 0.727470 \\
\hline The use of Products and Brands was Demonstrated in the Music Video & 0.734303 \\
\hline The Consumer is Familiar with the Products and Brands used in the Music Video & 0.756727 \\
\hline The Products and Brands Match the Image of the Artist & 0.745122 \\
\hline The Products and Brands were Placed in the Correct Context & 0.746916 \\
\hline The Consumer would have noticed the Products and Brands if they were Mentioned & 0.841883 \\
\hline
\end{tabular}

\subsubsection{Individual Factors (Realism)}

For the dimension of realism there are three variables of measurement.

The results of the full research survey indicate a Cronbach Alpha of 0.6025 The results show there is reliability as the Cronbach Alpha measurements are greater than 0.6. Comparisons of Cronbach Alpha scores to the previous study by Lee, Sung and de Gregoria regarding the cross cultural challenges in product placements, show that the realism component was found to be reliable with an overall score of 0.74 . The score in this study is fairly low $(0.6025)$.

Of the constructs in Lee, Sung and de Gregorio's study, further comparisons show consumers who prefer to see real products and brands as opposed to fictitious brands came to 0.86 , whereas in this study the score was extremely low, 0.556073 . Also consumers who believe the presence of real brands and products make the "television show" more realistic was 0.85 . In this study, adapted for music videos it came to 0.341486 . Finally the construct for whether consumers believe the character or artists use the brands and products in real life came to 0.51 , and in this study that value was greater and close to $0.6 ;(0.587710)$. The table below shows the Cronbach Alpha scores for the constructs.

Table 7: Cronbach Alpha Scores for Individual Factors (Realism)

\begin{tabular}{|l|c|}
\hline Cronbach Coefficient Alpha \\
\hline Total & 0.602567 \\
\hline Cronbach Coefficient Alpha with Deleted Variables \\
\hline Prefer to see Real Products and Brands than Fictitious Products and Brands in Music Videos & 0.556073 \\
\hline The Presence of Real Products and Brands makes the Music Video more Realistic & 0.341486 \\
\hline The Brands and products in the Music Video are Used by the Artist(s) in Real Life & 0.587710 \\
\hline
\end{tabular}

\subsubsection{Individual Factors (Attention and Influence)}

For the dimension of attention or influence there are four variables of measurement.

The results of the full research survey indicate a Cronbach Alpha of 0.657280 The results show the reliability is satisfactory as the Cronbach Alpha measurements is greater than 0.6. In the study conducted by Lee, Sung and de Gregoria on cross cultural challenges in product placements the Cronbach Alpha score for attention and influence was 
0.89. This is considerably higher than the score in this study $(0.657280)$. The table below shows the Cronbach Alpha scores for the constructs.

Table 8: Cronbach Alpha Scores for Individual Factors (Attention and Influence)

\begin{tabular}{|l|l|}
\hline Cronbach Coefficient Alpha & 0.657280 \\
\hline Total & 0.574488 \\
\hline Cronbach Coefficient Alpha with Deleted Variables & 0.552947 \\
\hline Bought Products and Brands Seen in Music Videos & 0.523442 \\
\hline Pay Attention to the Products and Brands Used by their Favorite Artists & 0.690076 \\
\hline Likely to Buy Products and Brands seen in Music Videos, rather than those in Commercials. \\
\hline Learned about New Products and Brands
\end{tabular}

Individual construct scores show consumers who have bought products and brands in music videos was 0.85 , for this study the score for that construct was 0.574488 . As for the score for the construct involving whether consumers pay attention to products and brands used by favourite characters (artists) was 0.84 , for this study, the score was 0.552947 . For the construct regarding whether consumers would be likely to buy products and brands in music videos, rather than those in commercials 0.79 , in this study the score was 0.523442 . Finally to test whether consumers learned about new products and brands, the Cronbach Alpha score was 0.68 , in this study it was slightly similar and scores 0.690076 .

\subsubsection{Individual Factors (Acceptance)}

For the dimension of acceptance there are six variables of measurement.

The results of the full research survey indicate a Cronbach Alpha of 0.657730 . The results show there is reliability as the Cronbach Alpha measurements is greater than 0.6.

Table 9: Cronbach Alpha Scores for Individual Factors (Acceptance)

\begin{tabular}{|c|c|}
\hline \multicolumn{2}{|l|}{ Cronbach Coefficient Alpha } \\
\hline Total & 0.657730 \\
\hline \multicolumn{2}{|l|}{ Cronbach Coefficient Alpha with Deleted Variables } \\
\hline Brand and Product Sponsors for Artists to be Indicated before the Airing of the Music Video & 0.626465 \\
\hline Placements of Products and Brands in Music Videos Should be Regulated & 0.606783 \\
\hline Hate seeing Products and Brands in Music Videos & 0.582128 \\
\hline Unethical to Influence Viewers Using Product and Brand Placements in Music Videos & 0.583988 \\
\hline Misleading and Deceptive Disguising Products and Brands as Props & 0.591015 \\
\hline Think the Music Video is like a Commercial for Products and Brands & 0.689119 \\
\hline
\end{tabular}

The Cronbach Alpha scores for the study by Lee, Sung and de Gregorio show scores of 0.86 for acceptance (ethics). The score for this study was much lower, 0.657730 . As for the individual construct comparisons, for whether it is unethical to influence viewers using product and brand placements in music videos scored 0.86 , for this study the score was substantially lower $(0.626465)$. For the scores regarding whether consumers felt mislead or deceived by the disguising of brands and products as props, the Cronbach Alpha was 0.85 , the score for this study was 0.591015 . For the construct whether consumers hates seeing products and brands in television shows (music videos) was 0.78 and for this study it was 0.582128 , much lower. The score for whether placements should be regulated in the Lee, Sung and de Gregorio was 0.77 , in comparison; the score for this study was 0.606783 . Regarding whether product and brand sponsors are to be indicated before the television show (music video) is aired was 0.68 , in this study the score was fairly close and was 0.626465 .

\subsection{Hypothesis Testing}

Linear regression analyses were used to test the hypotheses of the relationships in the model. This method involves examining data in terms of a linear model by indicating all the variables involved in the relationship and the effect of variables on each other. The level of significance chosen for the research is 0.05 ; this is the risk the researcher is prepared to take in being wrong about the outcome of the null hypotheses. 


\subsubsection{Hypothesis 1-Execution Stimulus and Brand Recall}

The first linear analysis tests the relationship between the execution stimulus and brand recall.

$\mathrm{HO}_{1}$ : There is no relationship between the execution of a stimulus and brand recall.

$\mathrm{H}_{1}$ : There is a relationship between the execution of a stimulus and brand recall.

Table 10: Linear Regression Analysis of the Execution Stimulus and Brand Recall

\begin{tabular}{|l|l|l|l|l|l|}
\hline Analysis of Variance & DF & Sum of Squares & Mean Squares & F Value & Pr $>\mathrm{F}$ \\
\hline Source & 1 & 1.18558 & 1.18558 & 69.07 & $<.0001$ \\
\hline Model & 418 & 7.17475 & 0.01716 & & \\
\hline Error & 419 & 8.36033 & & & \\
\hline Corrected Total & Coeff Var & Root MSE & Dependent Mean & R-Square & Adj R-Square \\
\hline & 7.48285 & 0.13101 & 1.75085 & 0.1418 & 0.1398 \\
\hline \multicolumn{7}{|l|l|}{} \\
\hline \multicolumn{7}{|l|l|l|l|}{} \\
\hline Varameter Estimates \\
\hline Variable & DF & Parameter Estimate & Standard Error & T Value & Pr $>\mathrm{F}$ \\
\hline Intercept & 1 & 1.48589 & 0.03252 & 45.70 & $<.0001$ \\
\hline Execution Stimulus & 1 & 0.07597 & 0.00914 & 8.31 & $<.0001$ \\
\hline
\end{tabular}

The $p$-value of the model is $<0.0001$. This is less than the level of significance, 0.05 . This means the model is significant and is a good fit for the data. The $p$-value of the intercept is $<0.0001$. This is less than the level of significance, 0.05 . This means the intercept is significant.

The $p$-value of the execution stimulus variable is $<0.0001$. This is less than the level of significance, 0.05 . This means the relationship is significant and there is sufficient evidence to reject the null hypothesis in favour of the alternative hypothesis, which states that there is a relationship between execution stimulus and brand recall. This means the relationship between execution stimulus and brand recall is significant.

The results are supported by the study by Balasubramanian, Karrh and Patwardhan (2006) which shows that the better the execution stimulus, the brand recall by the consumer improves. The study by Braun and Law (2000) confirms that the execution stimulus impacts on brand recall.

\subsubsection{Hypothesis 2- Execution Stimulus and Brand Recognition}

The second linear analysis tests the relationship between the execution stimulus and brand recognition.

$\mathrm{HO}_{2}$ : There is no relationship between the execution of a stimulus and brand recognition.

$\mathrm{H}_{2}$ : There is a relationship between the execution of a stimulus and brand recognition.

Table 11: Linear Regression Analysis of the Execution Stimulus and brand recognition

\begin{tabular}{|l|l|l|l|l|l|}
\hline Analysis of Variance & DF & Sum of Squares & Mean Squares & F Value & Pr $>$ F \\
\hline Source & 1 & 0.74777 & 0.74777 & 30.90 & $<.0001$ \\
\hline Model & 418 & 10.11696 & 0.02420 & & \\
\hline Error & 419 & 10.86473 & & & \\
\hline Corrected Total & Coeff Var & Root MSE & Dependent Mean & R-Square & Adj R-Square \\
\hline & 9.26402 & 0.15557 & 1.67933 & 0.0688 & 0.0666 \\
\hline \multicolumn{5}{|l|}{} \\
\hline Parameter Estimates & DF & Parameter Estimate & Standard Error & t Value & Pr $>\mathrm{F}$ \\
\hline Variable & DF & 0.03861 & 38.04 & $<.0001$ \\
\hline Intercept & 1 & 1.46891 & 0.01086 & 5.56 & $<.0001$ \\
\hline Execution Stimulus & 1 & 0.06034 & & \\
\hline
\end{tabular}

The results in the table below show that the p-value of the model is $<.0001$. This is less than the level of significance, 0.05. This means the model is significant and a good fit for the data. The $p$-value of the intercept is $<0.0001$. This is less than the level of significance, 0.05 . This means the intercept is significant. The $p$-value for the variable execution stimulus is $<.0001$. This is less than the level of significance which means the relationship is significant. There is sufficient evidence to reject the null hypothesis in favour of the alternative hypothesis, which states that there is a 
relationship between the execution stimulus and brand recognition. This means the relationship between execution stimulus and brand recognition is significant.

The results are supported by the findings of previous studies by Balasubramanian, Karrh and Patwardhan (2006) which shows that the execution stimulus impacts on brand recognition. The findings by Braun and Law (2000) also confirmed that successful execution stimulus enhances brand recognition.

\subsubsection{Hypothesis 3- Execution Stimulus and Brand Choice}

The third linear analysis tests the relationship between the execution stimulus and brand choice. $\mathrm{HO}_{3}$ : There is no relationship between the execution of a stimulus and brand choice.

$\mathrm{H}_{3}$ : There is a relationship between the execution of a stimulus and brand choice.

Table 12: Linear Regression Analysis of the Execution Stimulus and Brand Choice

\begin{tabular}{|l|l|l|l|l|l|}
\hline Analysis of Variance & DF & Sum of Squares & Mean Squares & F Value & Pr $>$ F \\
\hline Source & 1 & 4.52905 & 4.52905 & 81.16 & $<.0001$ \\
\hline Model & 418 & 23.32567 & 0.05580 & & \\
\hline Error & 419 & 27.85472 & & & \\
\hline Corrected Total & Coeff Var & Root MSE & Dependent Mean & R-Square & Adj R-Square \\
\hline \multicolumn{7}{|l|}{} & 1.85186 & 0.1626 & 0.1606 \\
\hline & 12.75617 & 0.23623 & Standard Error & t Value & Pr $>\mathrm{F}$ \\
\hline Parameter Estimates & Parameter Estimate & S & 22.75 & $<.0001$ \\
\hline Variable & DF & 0.05863 & 9.01 & $<.0001$ \\
\hline Intercept & 1 & 1.33399 & 0.01648 & & \\
\hline Execution Stimulus & 1 & 0.14849 &
\end{tabular}

The $p$-value of the model is $<0.0001$. This is less than the level of significance, 0.05 . This means the model is significant and is a good fit for the data. The $p$-value of the intercept is $<0.0001$. This is less than the level of significance, 0.05 . This means the intercept is significant.

The $p$-value of the execution stimulus variable is $<0.0001$. This is less than the level of significance, 0.05 . This means the relationship is significant and there is sufficient evidence to reject the null hypothesis in favour of the alternative hypothesis, which states that there is a relationship between the execution stimulus and brand choice. This means the relationship between execution stimulus and brand choice is significant.

The results are supported by the study by Balasubramanian, Karrh and Patwardhan (2006) which shows that as execution flexibility improves, the strategy enhances the desired message outcomes for the promotion. Successful execution contributes to the perceived value of the brand by the consumer as was confirmed by the study of Karrh, McKee \& Pardun (2003).

\subsubsection{Hypothesis 4- Individual Factors and Brand Recall}

The fourth linear analysis tests the relationship between the individual factors and brand recall.

$\mathrm{HO}_{4}$ : There is no relationship between the individual factors and brand recall.

$\mathrm{H1} 1$ : There is a relationship between the individual factors and brand recall.

Table 13: Linear Regression Analysis of the Individual Factors and Brand Recall

\begin{tabular}{|l|l|l|l|l|l|}
\hline Analysis of Variance & DF & Sum of Squares & Mean Squares & F Value & Pr $>$ F \\
\hline Source & 1 & 0.36606 & 0.36606 & 19.14 & $<.0001$ \\
\hline Model & 418 & 7.99427 & 0.01913 & & \\
\hline Error & 419 & 8.36033 & & & \\
\hline Corrected Total & Coeff Var & Root MSE & Dependent Mean & R-Square & Adj R-Square \\
\hline \multicolumn{7}{|l|}{} & 1.75085 & 0.0438 & 0.0415 \\
\hline & 7.89865 & 0.13829 & Standard Error & t Value & Pr>F \\
\hline Parameter Estimates & Parameter Estimate & 0.03598 & 44.37 & $<.0001$ \\
\hline Variable & DF & PF & 4.37 & $<.0001$ \\
\hline Intercept & 1 & 1.59623 & 0.01350 & & \\
\hline Individual Factors & 1 & 0.05905 &
\end{tabular}


The $p$-value of the model is $<0.0001$. This is less than the level of significance, 0.05 . This means the model is significant and is a good fit for the data. The $p$-value of the intercept is $<0.0001$. This is less than the level of significance, 0.05 . This means the intercept is significant.

The $p$-value of the variable, individual factors is $<0.0001$. This is less than the level of significance, 0.05 . This means the variable individual factors is significant. There is sufficient evidence to reject the null hypothesis in favour of the alternative hypothesis which states that there is a relationship between the individual factors and brand recall. The relationship between individual factors and brand recall is significant. The results are supported by the study by Balasubramanian, Karrh and Patwardhan (2006) which shows that individual factors are influential in yielding brand recall outcomes.

\subsubsection{Hypothesis 5- Individual Factors and Brand Recognition}

The fifth linear analysis tests the relationship between the individual factors and brand recognition.

$\mathrm{HO}_{5}$ : There is no relationship between the individual factors and brand recognition.

$\mathrm{H} 15_{5}$ : There is a relationship between the individual factors and brand recognition.

Table 14: Linear Regression Analysis of the Individual Factors and Brand Recognition

\begin{tabular}{|l|l|l|l|l|l|}
\hline Analysis of Variance & DF & Sum of Squares & Mean Squares & F Value & Pr $>$ F \\
\hline Source & 1 & 1.37277 & 1.37277 & 60.45 & $<.0001$ \\
\hline Model & 418 & 9.49196 & 0.02271 & & \\
\hline Error & 419 & 10.86473 & & & \\
\hline Corrected Total & Coeff Var & Root MSE & Dependent Mean & R-Square & Adj R-Square \\
\hline \multicolumn{7}{|l|}{} & 1.67933 & 0.1264 & 0.1243 \\
\hline \multicolumn{7}{|l|l|l|}{} \\
\hline Parameter Estimates & Standard Error & t Value & Pr $>$ F \\
\hline Variable & 8.97331 & 0.15069 & 0.03920 & 35.20 & $<.0001$ \\
\hline Intercept & DF & Parameter Estimate & 0.01471 & 7.78 & $<.0001$ \\
\hline Individual Factors & 1 & 1.37992 & 0.11435 & & \\
\hline
\end{tabular}

The results below show that the $p$-value of the model is $<0.0001$. This is less than the level of significance, 0.05 . This means the model is significant and is a good fit for the data. The p-value of the intercept is $<0.0001$. This is less than the level of significance, 0.05 . This means the intercept is significant.

The $p$-value of the variable, individual factors $<0.0001$. This is less than the level of significance, 0.05 . This means the variable individual factors is significant. This means the relationship between the variable individual factors and brand recognition is significant. There is sufficient evidence to reject the null hypothesis in favour of the alternative hypothesis which states that there is a relationship between the individual factors and brand recognition.

The relationship between individual factors and brand recognition is significant. The results are supported by the finding of Balasubramanian, Karrh and Patwardhan (2006) which shows that individual factors impact on brand recognition abilities of consumers.

\subsubsection{Hypothesis 6- Individual Factors and Brand Choice}

The sixth linear analysis tests the relationship between the individual factors and brand choice.

$\mathrm{HO}_{6}$ : There is no relationship between the individual factors and brand choice.

$\mathrm{H} 16_{6}$ : There is a relationship between the individual factors and brand choice.

Table 15: Linear Regression Analysis of the Individual Factors and Brand Choice

\begin{tabular}{|l|l|l|l|l|l|}
\hline Analysis of Variance & DF & Sum of Squares & Mean Squares & F Value & Pr $>$ F \\
\hline Source & 1 & 0.85548 & 0.85548 & 13.24 & 0.0003 \\
\hline Model & 418 & 26.99924 & 0.06459 & & \\
\hline Error & 419 & 27.85472 & & & \\
\hline Corrected Total & Coeff Var & Root MSE & Dependent Mean & R-Square & Adj R-Square \\
\hline & 13.72394 & 0.25415 & 1.85186 & 0.0307 & 0.0284 \\
\hline
\end{tabular}




\begin{tabular}{|l|l|l|l|l|l|}
\hline \multicolumn{5}{|l|}{ Parameter Estimates } \\
\hline Variable & DF & Parameter Estimate & Standard Error & t Value & Pr $>$ F \\
\hline Intercept & 1 & 1.61550 & 0.06612 & 24.43 & $<.0001$ \\
\hline Individual Factors & 1 & 0.09027 & 0.02480 & 3.64 & 0.0003 \\
\hline
\end{tabular}

The $p$-value of the model is 0.0003 . This is less than the level of significance, 0.05 . This means the model is significant and is a good fit for the data. The $p$-value of the intercept is $<0.0001$. This is less than the level of significance, 0.05 . This means the intercept is significant.

The $p$-value of the variable, individual factors is 0.0003 . This is less than the level of significance, 0.05 . This means the relationship between the variable individual factors and brand choice is significant. There is sufficient evidence to reject the null hypothesis in favour of the alternative hypothesis which states that there is a relationship between the individual factors and brand choice. The relationship between individual factors and brand choice is significant.

The results are supported by the study by Braun and Law (2000) which shows that consumer familiarity of a brand improves a chance of a brand being chosen and brand preference. The study by Balasubramanian, Karrh and Patwardhan (2006) indicated that individual factors of consumers is influential of implicit processing (brand choice) of placements.

\subsubsection{Hypothesis 7- Brand recall and Purchase Intention}

The seventh linear analysis tests the relationship between brand recall and purchase intention.

$\mathrm{HO}$ : There is no relationship between brand recall and purchase intention.

$\mathrm{H} 17$ : There is a relationship between brand recall and purchase intention.

Table 16: Linear Regression Analysis of the Brand Recall and Purchase Intention

\begin{tabular}{|l|l|l|l|l|l|}
\hline Analysis of Variance & DF & Sum of Squares & Mean Squares & F Value & Pr>F \\
\hline Source & 1 & 74.98437 & 74.98437 & 73.17 & $<.0001$ \\
\hline Model & 418 & 428.35810 & 1.02478 & & \\
\hline Error & 419 & 503.34248 & & & \\
\hline Corrected Total & Coeff Var & Root MSE & Dependent Mean & R-Square & Adj R-Square \\
\hline & 40.20159 & 1.01231 & 2.51810 & 0.1490 & 0.1469 \\
\hline \multicolumn{5}{|l|}{} \\
\hline Parameter Estimates & DF & Standard Error & T Value & Pr>F \\
\hline Variable & DFrameter Estimate & 0.31714 & -0.51 & 0.6107 \\
\hline Intercept & 1 & -0.16158 & 0.10153 & 8.55 & $<.0001$ \\
\hline Brand Recall & 1 & 0.86851 & & & \\
\hline
\end{tabular}

The $p$-value of the model is $<0.0001$. This is less than the level of significance, 0.05 . This means the model is significant and is a good fit for the data. The p-value of the intercept is 0.6107 . This is greater than the level of significance, 0.05 . This means the intercept is insignificant.

The $p$-value of the brand recall variable is $<0.0001$. This is less than the level of significance, 0.05 . This means the relationship is significant and there is sufficient evidence to reject the null hypothesis in favour of the alternative hypothesis, which states that there is a relationship between brand recall and purchase intention. The relationship between the brand recall and purchase intention is significant.

The results are supported by the findings of Braun and Law (2000) which shows that brand recall impacts on the effectiveness of product placements (where brand choice was the measure of product placement effectiveness).

\subsubsection{Hypothesis 8- Brand recognition and Purchase Intention}

The eighth linear analysis tests the relationship between brand recognition and purchase intention.

$\mathrm{HO}_{8}$ : There is no relationship between brand recognition and purchase intention.

$\mathrm{H}_{8}$ : There is a relationship between brand recognition and purchase intention. 
Table 17: Linear Regression Analysis of the Brand Recognition and Purchase Intention

\begin{tabular}{|l|l|l|l|l|l|}
\hline Analysis of Variance & DF & Sum of Squares & Mean Squares & F Value & Pr $>$ F \\
\hline Source & 1 & 95.05147 & 95.05147 & 97.31 & $<.0001$ \\
\hline Model & 418 & 408.29100 & 0.97677 & & \\
\hline Error & 419 & 503.34248 & & & \\
\hline Corrected Total & Coeff Var & Root MSE & Dependent Mean & R-Square & Adj R-Square \\
\hline & 39.24864 & 0.98832 & 2.51810 & 0.1888 & 0.1869 \\
\hline \multicolumn{5}{|l|}{} \\
\hline Parameter Estimates & DF & Parameter Estimate & Standard Error & t Value & Pr $>\mathrm{F}$ \\
\hline Variable & DF & 0.26000 & -0.01 & 0.9933 \\
\hline Intercept & 1 & -0.00219 & 0.08977 & 9.86 & $<.0001$ \\
\hline Brand Recognition & 1 & 0.88554 & & \\
\hline
\end{tabular}

The $p$-value of the model is $<0.0001$. This is less than the level of significance, 0.05 . This means the model is significant and is a good fit for the data. The p-value of the intercept is 0.9933 . This is greater than the level of significance, 0.05 . This means the intercept is insignificant. The $p$-value of the brand recognition variable is $<0.0001$. This is less than the level of significance, 0.05 . This means the relationship is significant and there is sufficient evidence to reject the null hypothesis in favour of the alternative hypothesis, which states that there is a relationship between brand recognition and purchase intention. This means the relationship between brand recognition and purchase intention is significant. The results are supported by the study by Braun and Law (2000) which shows that brand recognition impacts on brand choice (where brand choice was a measure of product placement effectiveness).

\subsubsection{Hypothesis 9-Brand Choice and Purchase Intention}

The ninth linear analysis tests the relationship between brand choice and purchase intention.

$\mathrm{HO}_{\mathrm{g}}$ : There is no relationship between brand choice and purchase intention.

$\mathrm{H} 1 \mathrm{~g}$ : There is a relationship between brand choice and purchase intention.

Table 18: Linear Regression Analysis of the Brand Choice and Purchase Intention

\begin{tabular}{|l|l|l|l|l|l|}
\hline Analysis of Variance & DF & Sum of Squares & Mean Squares & F Value & Pr>F \\
\hline Source & 1 & 137.97187 & 137.97187 & 157.85 & $<.0001$ \\
\hline Model & 418 & 365.37061 & 0.87409 & & \\
\hline Error & 419 & 503.34248 & & & \\
\hline Corrected Total & Coeff Var & Root MSE & Dependent Mean & R-Square & Adj R-Square \\
\hline & 37.12842 & 0.93493 & 2.51810 & 0.2741 & 0.2724 \\
\hline \multicolumn{5}{|l|}{} \\
\hline Parameter Estimates & Parameter Estimate & Standard Error & t Value & Pr>F \\
\hline Variable & DF & 0.18140 & 1.72 & 0.0859 \\
\hline Intercept & 1 & 0.31227 & 0.05022 & 12.56 & $<.0001$ \\
\hline Brand Choice & 1 & 0.63101 & & \\
\hline
\end{tabular}

The $p$-value of the model is $<0.0001$. This is less than the level of significance, 0.05 . This means the model is significant and is a good fit for the data. The $p$-value of the intercept is 0.0859 . This is greater than the level of significance, 0.05 . This means the intercept is insignificant. The $p$-value of the brand choice variable is $<0.0001$. This is less than the level of significance, 0.05 . This means the relationship is significant and there is sufficient evidence to reject the null hypothesis in favour of the alternative hypothesis, which states that there is a relationship between brand choice and purchase intention. This means the relationship between brand choice and purchase intention is significant.

The result is supported by the research conducted by Braun and Law (2000) which shows that implicit processing (brand choice) independently influences product placement effectiveness (where brand choice was a measure of effectiveness). The study by Balasubramanian, Karrh and Patwardhan (2006) confirms that implicit processing (brand choice) enhances purchase intention.

The above analyses show that the variables brand recall, brand recognition and brand choice all influence the purchase intentions of consumers significantly. There are also significant relationships between the individual factors and 
brand recall, brand recognition and brand choice that subsequently influence purchase intention. The relationships between execution stimulus and brand recall, brand recognition and brand choice are significant.

These results were confirmed by previous studies by Braun and Law (2000) and Balasubramanian, Karrh and Patwardhan (2006); on which the proposed model was based.

\subsection{ANOVA (One Way Analysis)}

The ANOVA was used to determine if there was a difference in responses to purchase intentions given the differing gender, income and age of respondents. If a difference existed then the source of the difference was further detected. This brings forward the final hypothesis to be tested

\subsubsection{Hypothesis 10- Gender, Income, Age and Purchase Intention}

$\mathrm{HO}_{10}$ : There is no difference in responses of people of differing age, gender and income in relation to purchase intention.

$\mathrm{H}_{10}$ : There is a difference in responses of people of differing age, gender and income in relation to purchase intention.

\subsubsection{Gender and Purchase Intention}

$\mathrm{HO}_{10} \mathrm{a}$ : There is no difference in responses of men and women in relation to purchase intention, after being exposed to product placements in music videos.

$\mathrm{H}_{10 \mathrm{a}}$ : There is a difference in responses of men and women in relation to purchase intention, after being exposed to product placement in music videos.

Table 19: One Way Analysis of the Gender and Purchase Intention

\begin{tabular}{|l|l|l|l|l|l|}
\hline Analysis of Variance & DF & Sum of Squares & Mean Squares & F Value & Pr $>\mathrm{F}$ \\
\hline Source & 1 & 3.1297629 & 3.1297629 & 2.62 & 0.1066 \\
\hline Model & 418 & 500.2127133 & 1.1966811 & & \\
\hline Error & 419 & 503.3424762 & & & \\
\hline Corrected Total & Coeff Var & Root MSE & Purchase Intention Mean & R-Square & \\
\hline \multicolumn{7}{|l|}{} \\
\hline \multicolumn{7}{|l|}{} & 43.44273 & 1.093929 & 2.518095 & 0.006218 & \\
\hline Parameter Estimates & DF & ANOVA SS & Mean Square & F Value & Pr $>\mathrm{F}$ \\
\hline Variable & 1 & 3.12976286 & 3.12976286 & 2.62 & 0.1066 \\
\hline Demographics- Gender & 1
\end{tabular}

The results show that the $p$-value for the variable gender is 0.1066 . This value is greater than the level of significance, 0.05. This means that the relationship between gender and purchase intention is insignificant, there is insufficient evidence to reject the null hypothesis in favour of the alternative hypothesis. There is no difference in responses of men and women in relation to purchase intention, after being exposed to product placements in music videos. The product placement strategy in music videos is equally effective in targeting both males and females. These results are supported by the study of Van der Waldt, Du Preez and Williams (2007) which shows that consumers (male or female) had neutral feelings toward placement strategies.

\subsubsection{Age and Purchase Intention}

$\mathrm{H}_{10 \mathrm{~b}}$ : There is no difference in responses of consumers of differing age in relation to purchase intention, after being exposed to product placements in music videos.

$\mathrm{H}_{1}{ }_{10 \mathrm{~b}}$ : There is a difference in responses of consumers of differing age in relation to purchase intention, after being exposed to product placement in music videos. 
Table 20: One Way Analysis of the Age and Purchase Intention

\begin{tabular}{|l|l|l|l|l|l|}
\hline Analysis of Variance & DF & Sum of Squares & Mean Squares & F Value & Pr>F \\
\hline Source & 4 & 7.3569570 & 1.8392393 & 1.54 & 0.1900 \\
\hline Model & 415 & 495.9855192 & 1.1951458 & & \\
\hline Error & 419 & 503.3424762 & & & \\
\hline Corrected Total & Coeff Var & Root MSE & Purchase Intention Mean & R-Square & \\
\hline \multicolumn{7}{|l|}{} & 2.518095 & 0.014616 & \\
\hline \multicolumn{7}{|l|}{} & \multicolumn{5}{l|}{} \\
\hline Parameter Estimates & 43.41485 & 1.093227 & F Value & Pr>F \\
\hline Variable & DF & ANOVA SS & Mean Square & 1.54 & 0.1900 \\
\hline Demographics- Age & 4 & 7.35695703 & 1.83923926 & & \\
\hline
\end{tabular}

The results show that the $p$-value for the variable age is 0.1900 . This value is greater than the level of significance, 0.05 . This means that the relationship between age and purchase intention is insignificant, there is insufficient evidence to reject the null hypothesis in favor of the alternative hypothesis. There is no difference in responses of consumers of differing age in relation to purchase intention, after being exposed to product placements in music videos.

The product placement strategy in music videos is equally effective in targeting consumers of different ages within the Y generation. The results are supported by the study of Van der Waldt, Du Preez and Williams (2007) which shows that consumers (aged 18-24) responded to product placement in the same way. (This may not account for the entire age group of the $Y$ generation, but this study was the closest matching result). A study that is more accurate, by Chen and Deterding (2013) shows that college aged consumers were more accepting of placements in media.

\subsubsection{Income and Purchase Intention}

$\mathrm{HO}_{10} \mathrm{C}$ : There is no difference in responses of consumers of differing income brackets in relation to purchase intention, after being exposed to product placements in music videos.

$\mathrm{H}_{10} \mathrm{C}$ : There is a difference in responses of consumers of differing income brackets in relation to purchase intention, after being exposed to product placement in music videos.

Table 21: One Way Analysis of the Income and Purchase Intention

\begin{tabular}{|c|c|c|c|c|c|}
\hline \multicolumn{6}{|l|}{ Analysis of Variance } \\
\hline Source & DF & Sum of Squares & Mean Squares & F Value & $\mathrm{Pr}>\mathrm{F}$ \\
\hline Model & 4 & 1.2546663 & 0.3136666 & 0.26 & 0.9039 \\
\hline Error & 415 & 502.0878099 & 1.2098501 & & \\
\hline \multirow[t]{3}{*}{ Corrected Total } & 419 & 503.3424762 & & & \\
\hline & Coeff Var & Root MSE & Purchase Intention Mean & R-Square & \\
\hline & 43.68111 & 1.099932 & 2.518095 & 0.002493 & \\
\hline \multicolumn{6}{|l|}{ Parameter Estimates } \\
\hline Variable & DF & ANOVA SS & Mean Square & F Value & Pr>F \\
\hline Demographics-Income & 4 & 1.25466629 & 0.31366657 & 0.26 & 0.9039 \\
\hline
\end{tabular}

The results show that the $p$-value for the variable age is 0.9039 . This value is greater than the level of significance, 0.05 . This means that the relationship between income and purchase intention is insignificant, there is insufficient evidence to reject the null hypothesis in favor of the alternative hypothesis. There is no difference in responses of consumers of differing income brackets in relation to purchase intention, after being exposed to product placements in music videos. The product placement strategy in music videos is equally effective in targeting consumers of differing income brackets. These results are supported by the study of Chen and Deterding (2013) which shows that consumers (college aged and which share similar characteristics of college consumers, such as income and spending patterns) have grown to accept placement strategies.

\section{Conclusions}

The hypotheses were tested using linear regression analyses. The linear regression analyses were instrumental in achieving the purpose of the study, to determine if product placements in music videos are effective. The results show 
that hypotheses 1-9 were significant (the relationships were significant). The results indicated that individual factors have a significant impact on the respondent's brand recall, brand recognition and brand choice after being exposed to product placements in a music video. The execution stimulus has a significant impact on the respondent's brand recall, brand recognition and brand choice. Subsequently, brand recall, brand recognition and brand choice have a significant impact on the respondent's purchase intention. The results of the linear regression results show, given that purchase intention is the measure of effectiveness of placements, product placements in music videos are effective in targeting the South African $Y$ generation. This will be further elaborated.

ANOVA (one way analysis) was used to test hypothesis 10 . The results for hypothesis 10 were insignificant (the relationships were insignificant). The moderator variables (gender, age and income) do not have a significant influence on the respondent's purchase intention.

$T$ tests confirmed that the respondent's responses regarding purchase intention for males and females (respondents of differing genders). T tests further revealed that there was a significant difference in purchase intention for respondents who liked the artists in the music video and those who did not. There was a significant difference in purchase intention for respondents who liked the genre of the music video and for those who did not. There was a significant difference in purchase intention for respondents who liked the music video and those respondents who did not. However there was an insignificant difference in purchase intention of respondents who recognized the artists in the music video and those who did not. Furthermore, there was a significant difference in purchase intentions of respondents who watch music videos and those who do not. There was a significant difference in purchase intentions of respondents who watched music videos using the internet and those who did not. However there was an insignificant difference in purchase intention of respondents who watched music videos on television and those who did not.

\subsection{Execution Stimulus and Brand Recall}

The first finding shows that there is a relationship between the execution stimulus of a music video with placements and the brand recall of those placements. The execution of the music video containing placements (visibility, centrality of focus, seamless integration and demonstration, familiarity, context and image fit, and mode (visual/audio)) contribute to the consumer's ability to recall the products and brands placements (recall the placements, remember where the placements were located, remember how the consumers felt after being exposed to the placements, improved awareness of the products and brands, ability to remember the brands and products at a later stage, distractions which may have influenced recall ability or the length of the placements which may have influenced recall).

\subsection{Execution Stimulus and Brand Recognition}

The second finding shows that there is a relationship between the execution stimulus of a music video with placements and brand recognition of those placements. The execution of the music video containing placements (visibility, centrality of focus, seamless integration and demonstration, familiarity, context and image fit, and mode (visual/audio)) contribute to the consumer's ability to recognize the products and brands placements (ability to notice brands and products in the music video, ability to recognize those brands and products, consider the popularity of those brands and products, the placements remind consumers of commercials of those products and brands, consumer uses and is familiar with those brands and products, consumers feel the brands and products placements are overwhelming).

\subsection{Execution Stimulus and Brand Choice}

The third finding shows that that there is a relationship between the execution stimulus of a music video with placements and the brand choice which positively influences the purchase intentions of the consumer. The execution of the music video containing placements (visibility, centrality of focus, seamless integration and demonstration, familiarity, context and image fit, and mode (visual/audio)) contribute in influencing the consumer's choice of products and brands (the consumer thinks the products and brands are acceptable, the consumer trusts the brands and products, the consumer would choose the products and brands for him or her and for his or her family and friends, the consumer thinks the brands and products are appropriate).

\subsection{Individual Factors and Brand Recall}

The fourth finding shows there is a relationship between the individual factors of the consumer and the brand recall of 
placements in the music video. The individual factors of the consumer (perceived realism (prefer to see real brands as opposed to fictitious brands, find real brands make the music video more realistic and expect that artist(s) use the placed brands and products in real life), attention and influence (consumers have learned about new brands and products after having watched the music video, consumers are more likely to buy brands and products observed in music videos than commercials, consumers are more likely to pay attention to the brands and products their favourite artist(s) use, consumers have bought products and brands seen in music videos), acceptance (consumers did not perceive the music video as an advertisement for products and brands, consumers thoughts on the ethical status of placements in music videos, consumers feelings of deception by products and brands disguised as props and items, consumers opinion on seeing brands and products in music videos, consumers thoughts on the regulation of placements and on whether brand and product sponsors should be indicated before the music video is aired) contribute to the consumer's ability to recall the products and brands placements (recall the placements, remember where the placements were located, remember how the consumers felt after being exposed to the placements, improved awareness of the products and brands, ability to remember the brands and products at a later stage, distractions which may have influenced recall ability or the length of the placements which may have influenced recall).

\subsection{Individual Factors and Brand Recognition}

The fifth finding shows there is a relationship between the individual factors of the consumer and the brand recognition of placements in the music video. The individual factors of the consumer (perceived realism (prefer to see real brands as opposed to fictitious brands, find real brands make the music video more realistic and expect that artist(s) use the placed brands and products in real life), attention and influence (consumers have learned about new brands and products after having watched the music video, consumers more likely to buy brands and products observed in music videos than commercials, consumers are more likely to pay attention to the brands and products their favourite artist(s) use, consumers have bought products and brands seen in music videos), acceptance (consumers did not perceive the music video as an advertisement for products and brands, consumers thoughts on the ethical status of placements in music videos, consumers feelings of deception by products and brands disguised as props and items, consumers opinion on seeing brands and products in music videos, consumers thoughts on the regulation of placements and on whether brand and product sponsors should be indicated before the music video is aired) contribute to the consumer's ability to recognize the products and brands placements (ability to notice brands and products in the music video, ability to recognize those brands and products, consider the popularity of those brands and products, the placements remind consumers of commercials of those products and brands, consumer uses and is familiar with those brands and products, the consumers feel the brands and products placements are overwhelming).

\subsection{Individual Factors and Brand Choice}

The sixth finding shows there is a relationship between the individual factors of the consumer and the brand choice. The individual factors of the consumer (perceived realism (prefer to see real brands as opposed to fictitious brands, find real brands make the music video more realistic and expect that artist(s) use the placed brands and products in real life), attention and influence (consumers have learned about new brands and products after having watched the music video, consumers more likely to buy brands and products observed in music videos than commercials, consumers are more likely to pay attention to the brands and products their favorite artist(s) use, consumers have bought products and brands they have seen in music videos), acceptance (consumers did not perceive the music video as an advertisement for products and brands, consumers thoughts on the ethical status of placements in music videos, consumers feelings of deception by products and brands disguised as props and items, consumers opinion on seeing brands and products in music videos, consumers thoughts on the regulation of placements and on whether brand and product sponsors should be indicated before the music video is aired) all contribute in influencing the consumers choice of products and brands (consumer thinks the products and brands are acceptable, the consumer trusts the brands and products, the consumer would choose the products and brands for him or her and for his or her family and friends, the consumer thinks the brands and products are appropriate).

\subsection{Brand Recall and Purchase Intention}

The seventh finding shows there is a relationship between brand recall and purchase intention. The ability of consumers to recall the brand and product placements (brand recall- recall the placements, remember where the placements were 
located, remember how the consumers felt after being exposed to the placements, improved awareness of the products and brands, ability to remember the brands and products at a later stage, distractions which may have influenced recall ability or the length of the placements which may have influenced recall) influences the purchase intention of the consumer (consider buying the product or brand, search for information about the products and brands, inquire about the products and brands at the local store, look for the products and brands at a local store and plan to buy the products and brands in the near or distant future).

\subsection{Brand Recognition and Purchase Intention}

The eighth finding shows there is a relationship between brand recognition and purchase intention. The consumer's ability to recognize a brand or product in a placement (brand recognition- ability to notice brands and products in the music video, ability to recognize those brands and products, consider the popularity of those brands and products, the placements remind consumers of commercials of those products and brands, consumer uses and is familiar with those brands and products, the brands and products placements are overwhelming) influences the purchase intention of the consumer (consider buying the product or brand, search for information about the products and brands, inquire about the products and brands at the local store, look for the products and brands at a local store and plan to buy the products and brands in the near or distant future).

\subsection{Brand Choice and Purchase Intention}

The ninth finding shows there is a relationship between brand choice and purchase intention. Brand choice (consumer thinks the products and brands are acceptable, the consumer trusts the brands and products, the consumer would choose the products and brands for him or her and for his or her family and friends, the consumer thinks the brands and products are appropriate) influences the purchase intention of the consumer (consider buying the product or brand, search for information about the products and brands, inquire about the products and brands at the local store, look for the products and brands at a local store and plan to buy the products and brands in the near or distant future).

\subsection{Demographics, Consumer Behavior, Attitude towards the Music Video and Purchase Intention}

The tenth finding shows that; by means of an ANOVA (one way analysis) there were no significant differences in purchase intentions of males and females, respondents of differing income brackets and consumers of differing ages within the $Y$ generation, after being exposed to product placements in a music video.

\section{Modified Theoretical Model}

Given the relationships that were tested, it was not necessary to modify the model as all relationships proposed in the hypotheses prevailed. However the model showing the relationships is shown below with the correlating p-values.

The relationship between brand choice and purchase intention is the strongest positive linear relationship.

Figure 2: Model of Audience Response to Product Placement in Music Videos

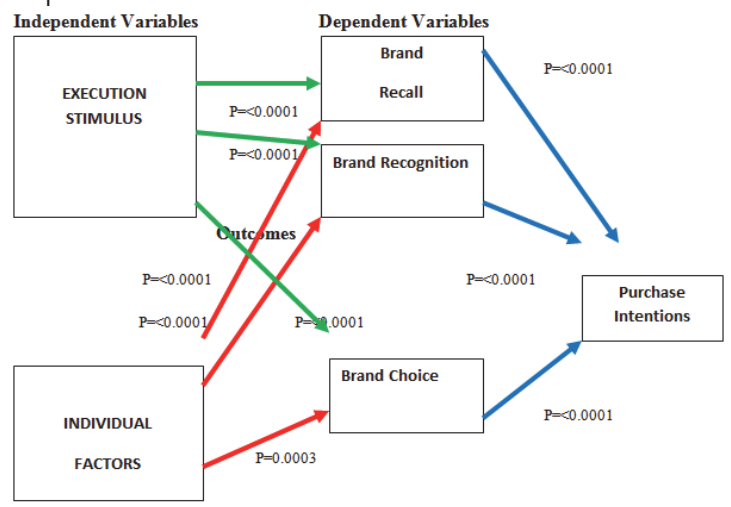




\section{Recommendations and Managerial Implications}

\subsection{Managerial Implications}

The research findings contribute to the knowledge and improvements to be made to the marketing strategies for brands and products to appropriately target the South African Y generation.

The main implications marketers need to take note of, is that actions of brand recall, brand recognition and brand choice definitely impact on the purchasing intentions of consumers. This means marketers must employ effective product and brand placement strategies that aid brand recall, brand recognition and brand choice. The strongest positive relationship in the model is between brand choice and purchase intention.

As for individual factors marketers cannot change the individual factors of consumers; these are decided attitudes and perceptions on which consumers. Further research can involve finding ways for marketing strategies to appeal to consumer perceptions and attitudes regarding placement strategies so that consumers will be more receptive of placements to enhance the subsequent brand recall, brand recognition and brand choice.

Table 22: Managerial Implications For Each Hypothesis

\begin{tabular}{|c|c|}
\hline Hypotheses & Managerial implications \\
\hline $\begin{array}{l}\mathrm{H}_{1} \text { : Relationship between the execution of a stimulus } \\
\text { and brand recall. }\end{array}$ & $\begin{array}{l}\text { Use the execution stimulus (the music video and the placements in the video) to prompt better } \\
\text { brand recall. E.g. have characters using the placements. }\end{array}$ \\
\hline $\begin{array}{l}\mathrm{H}_{2} \text { : Relationship between the execution of a stimulus } \\
\text { and brand recognition. }\end{array}$ & $\begin{array}{l}\text { Use the execution stimulus (the music video and the placements in the video) to prompt better } \\
\text { brand recognition. E.g. display placements more frequently, for longer periods. }\end{array}$ \\
\hline $\begin{array}{l}\mathrm{H}_{4}: \text { Relationship between the individual factors and } \\
\text { brand recall. }\end{array}$ & $\begin{array}{l}\text { Rely on individual factors to prompt brand recall. E.g. consumer's previous experience with a } \\
\text { product. }\end{array}$ \\
\hline $\begin{array}{l}\mathrm{H}_{5} \text { : Relationship between the individual factors and } \\
\text { brand recognition }\end{array}$ & $\begin{array}{l}\text { Rely on individual factors to prompt brand recognition. E.g. consumer's previous exposure to a } \\
\text { product. }\end{array}$ \\
\hline $\begin{array}{l}\mathrm{H}_{6} \text { : Relationship between the individual factors and } \\
\text { brand choice. }\end{array}$ & $\begin{array}{l}\text { Rely on individual factors to prompt brand choice. E.g. consumer's attitude towards favourable } \\
\text { characters using products and favourable perceptions of products. }\end{array}$ \\
\hline $\begin{array}{l}\mathrm{H}_{7} \text { : Relationship between brand recall and purchase } \\
\text { intention. }\end{array}$ & $\begin{array}{l}\text { brand recall to influence purchase intentions. E.g. Consumer's previous experience with } \\
\text { d or product. }\end{array}$ \\
\hline $\begin{array}{l}\text { H8: Relationship between brand recognition and } \\
\text { purchase intention. }\end{array}$ & $\begin{array}{l}\text { n brand recognition to influence purchase intentions. E.g. Consumer's previous exposure } \\
\text { and or product. }\end{array}$ \\
\hline $\begin{array}{l}\mathrm{H}_{9}: \text { Relationship between brand choice and purchase } \\
\text { intention. }\end{array}$ & $\begin{array}{l}\text { Placements should be portrayed in a way that consumers } \\
\text { acceptable, appropriate and trusted and would be willing to choos } \\
\text { for themselves, friends and family. }\end{array}$ \\
\hline $\begin{array}{l}\mathrm{H}_{10 \mathrm{a}} \text { : Difference in responses of men and women in } \\
\text { relation to purchase intention, after being exposed to } \\
\text { product placement in music videos. }\end{array}$ & $\begin{array}{l}\text { Marketers do not have to target females and males differently when using placem } \\
\text { No unnecessary efforts and investments directed at promotional strategies to targe } \\
\text { differently and separately. }\end{array}$ \\
\hline $\begin{array}{l}\mathrm{H}_{10 \mathrm{~b}} \text { : Difference in responses of consumers of differing } \\
\text { age in relation to purchase intention, after being } \\
\text { exposed to product placement in music videos. }\end{array}$ & $\begin{array}{l}\text { Technological devices, fashionable items, car brands and alcoholic beverages are appropriate } \\
\text { items for } Y \text { generation consumers to consider purchasing (neither beyond the income range and } \\
\text { preference of the age group). }\end{array}$ \\
\hline $\begin{array}{l}\mathrm{H}_{10 c} \text { : Difference in responses of consumers of differing } \\
\text { income brackets in relation to purchase intention, after } \\
\text { being exposed to product placement in music videos. }\end{array}$ & $\begin{array}{l}\text { These factors are insignificant in influencing the purchase intentions of consumers, despite the } \\
\text { differing purchasing power of respondents given the income levels and the preferences } \\
\text { attributable to differing age groups within the } Y \text { generation, placements work as promotion } \\
\text { startegies targeting the } Y \text { generation. }\end{array}$ \\
\hline
\end{tabular}

The study contributed to the current knowledge of product placement as a promotional strategy, particularly using the medium of music videos. Findings show that purchase intentions for consumers who watch music videos and those who do not, differ significantly. Marketers should use this information to target music video "watchers" as a viable market segment, thus tailoring promotional strategies accordingly to better target this segment.

Given the different dynamics of the $Y$ generation living in South Africa, the differing purchase intentions of those respondents who watch music videos on the internet are significant, but those who watch music videos on television are insignificant. This information is useful for marketers in creating market segments to target individuals. Most consumers who have access to the internet either live and work or commute to affluent areas where the luxury of internet access can be enjoyed. These are consumers who can be targeted as separate segments within the Y generation market.

\subsection{Recommendations}

The model developed indicating the audience response to product placement has been altered specifically for the 
medium of music videos, which had previously been neglected as a research area in product placement. News articles that had alluded to the profitable reach of music videos to adolescent audiences were not far from the truth. This international platform, aided with the advantageous life span of placements makes for a lucrative contributor to the knowledge and awareness of brands, long after products become outdated (which is possible given the high-paced innovation of products).

As part of integrated marketing communications made possible by technology and high-speed internet innovations, consumers have better access to music videos than ever before. Further research can focus on the technologies and innovations that make it possible for music videos to travel internationally, at high rates, reaching millions of $Y$ generation consumers all over the world.

As a research area that was not tackled in this study, the role of celebrity endorsements (musicians) having products and brands that they endorse as placements in music videos should be investigated for effectiveness in influencing purchase intentions. (This will be useful information for marketers, especially now that artists are releasing clothing brands, perfumes and technology and using or placing these new products in their music videos. Examples of artists who do this include Britney Spears and Jennifer Lopez).

The influence of product placements in being effective in creating brand awareness for new products and brands should be investigated.

\section{Limitations}

There are several limitations to this research; these should be noted for future research endeavours in this area to ensure refined research in the future by avoiding these flaws.

Due to time and monetary constraints, the study was only conducted once, from a single sample, of 420 . The video was only observed once, the effectiveness of having watched the music video more than once was not considered.

The placement of specified brands was not investigated, and the study was limited to the brands and products placed in the music video. No provision was made for an array of possible brands that are relevant to $Y$ generation consumers. There was also no difference in the nature of the products and brands which would be relevant for certain market segments (for example feminine products for the female market segment and masculine products for the male market segment) only neutral products and brands were present in the music video.

The limited and generalized brand selection means that the effectiveness of the placement promotional strategy of a specific brand in relation to competitors could not be measured. This also presents a future research area, where the effectiveness of product placements in music videos can be better analyzed with comparative analysis with competitive brands (Van Der Waldt et al, 2007b). Brands were not also specifically identified and this means current brand attitudes and perceptions could not be measured relative to improved or depreciated perceptions and attitudes that may have or may not have arisen due to placements of these brands and products in music videos (Van Der Waldt et al, 2008a).

The music video (stimulus) also presents more limitations as the study only draws conclusions based on responses of this particular video. For example, the effects of placements that were visually presented will only be determined. The effects of placements in differing modes (audio and audiovisual), differing song genres, differing artists, differing centrality and subtlety of focus will not be measured. This limits the generalizability of the results for different music videos. Future research should take into account all the differing aspects to be tested when measuring effectiveness to ensure better generalizability. (This may involve using more than one music video to cover all the different aspects of placements, however will require more time and less monetary constraints to accomplish this).

The effects observed in the artificial research environment may not be guaranteed in real life viewing of music videos (Van Der Waldt et al, 2007b). The study was conducted in a controlled academic environment without any distractions. There is no guarantee that responses will be the same in a real life atmosphere with distractions. Even though the study seeks to determine if consumers will make purchase intentions based on brand and product placements, a problem is that often what people plan to do, does not always happen, there is no way in proving that consumers will follow through with the planned purchase intentions until the actual purchase and there are no resources of time and finance to collect this information. The research is one sided, and from the consumer's perspective only, future research should consider the costs to companies and brands in placing brands and products in music videos to determine the feasibility and possibly measure the returns of the strategy better (Van Der Waldt et al, 2008b).

Voluntary bias was introduced to the random sample selection (undergraduates aged 18-27) as responses could not be collected from respondents aged between 28-31 (Van Der Waldt et al, 2007a). Only willing volunteers gave responses and thus a voluntary bias was introduced, this means responses from non-volunteers were lost. More females were willing to answer than males. There was also the possibility of response bias as there was no delay between 
watching the video and answering the questionnaire, so all recall responses were biased by the limited delay.

\section{Opportunities for Future Research}

A future research direction would be to take measures after repeated observation of the execution stimulus (music video) which may also provide more accurate recall results.

Future research can focus on the effectiveness of specified brands and products for specified brand communities (although it is necessary to get permission from companies to have brands and promotional strategies investigated), for example, study the placement of Apple products and the influence of the purchase intentions of individuals in the brand community. Furthermore research should compare the effectiveness of placements for high and low involvement products and how that further influences the purchase intentions of consumers. This will also indicate for which products and brands the placement strategy works better.

Future research should counter response bias which may have influenced recall ability of respondents. A follow up study one week and possibly two weeks after exposure to the music video could prove to be a better measure of recall ability.

\section{References}

Balasubramanian, S.K., Karrh, J.A., Patwardhan, H. (2006). Audience Response to Product Placements: An Integrative Framework and Research Agenda. Journal of Advertising, 35(3), 115-141. DOI 10.2753/JOA0091-3367350308

Braun, K. A., Law, S. (2000). I'll Have What She's Having: Gauging the Impact of Product Placement's on Viewers. Psychology and Marketing, 17(2), 1059-1075. Retrieved from John Wiley \& Sons Inc.

Cheng, X., Dale, C., Liu, J. (2007). Understanding the Characteristics of Internet Short Video Sharing: YouTube as a Case Study arXiv. Retrieved from http://arxiv.org/pdf/0707.3670.pdf

Galpin, J.S., Krommenhoek, R. (2013). Course Notes for Statistical Research Design and Analysis. University of the Witwatersrand.

Gordon, W., Valentine, V. (2000). The 21st Century Consumer- A new Model of Thinking. Paper presented at the MRS Conference. Retrieved from http://www.acacia-avenue.com/media/128326077321st_Century_Consumer.pdf

Gupta, P.B., Balasubramanian, S.K, Klassen, M.L. (2000). Viewers Evaluations of Product Placements in Movies: Public Policy Issues and Managerial Implications. Journal of Current Issues and Research in Advertising, 22(2), 41-52.

Gupta, P.B., Gould, S.J. (1997). Consumers' Perceptions of Ethics and Acceptability of Product Placements in Movies: Product Category and Individual Differences. Journal of Current Issues and Research in Advertising, 19(1), 37-50. Retrieved from Ebsco Publishing.

Gupta, P.B., Lord, K.R. (1998). Product Placement in Movies: The Effect of Prominence and Mode of Audience Recall. Journal of Current Issues and Research in Advertising, 20(1), 47-59. Retrieved from Ebscohost Publishing.

Karbasfrooshan, A. (2011, May 2). The Growth of Product Placement in music Videos. Online Video Insider. Retrieved from http://www.mediapost.com/publications/article/149688/\#axzz2NyPDptDx

Karrh, J. A., McKee, K.B., Pardun, C.J. (2003). Practitioners' Evolving Views on Product Placement. Effectiveness Journal of Advertising in Research, 138-149. DOl: 10.1017/S0021849903030198

Lawson-Body, L., Limayem, M. (2004). The Impact of Customer Relationship Management on Customer Loyalty: The Moderating Role of Website Characteristics. JCMC, 9(4). Retrieved from http://jcmc.indiana.edu/vol9/issue4/lawson_body.html

Lee, T. D., Sung, Y., de Gregorio, F. (2010). Cross-cultural Challenges in Product Placement Marketing Intelligence and Planning. Marketing Intelligence and Planning, 29(4), 366-384. DOI 10.1108/02634501111138545

Malhotra, N.K. (2009). Marketing Research: An Applied Orientation (6th ed.). Pearson

MicrosoftSouthAfrica. Internet Explorer 10- Child of the 90's [video online] Available at http://www.youtube.com/watch?v=2_Qnv-xN5jo [Accessed 17 February 2013]

My Broadband. (2012). South African Viewer Stats Released 2012. Retrieved from http://mybroadband.co.za/news/general/64610-southafrican-tv-viewer-stats-released.html

Neer, K. (2003). How Product Placement Works. HowStuffWork.com (2013) Retrieved from http://money.howstuffworks.com/productplacement.htm

Nuttall, S. (2004). Stylizing Thyself: The Generation Y in Rosebank, Johannesburg Public Culture .16(3), 430-452. Retrieved from Duke University Press

Percy, L. (2006). Are Product placements Effective? International Journal of Advertising, 25(1), 112-114. Retrieved from WARC World Advertising Research Centre

Plambeck, J. (2010, July 5). Product Placement Grows in Music Videos. The New York Times. Retrieved from http://www.nytimes.com/2010/07/06/business/media/06adco.html?_r=0

Russell, C.A. (2002). Investigating the Effectiveness of Product Placements in Television Shows: The Role of Modality and Plot Connection Congruence on Brand Memory and Attitude. Journal of Consumer Research, 29, 307-318. Retrieved from Journal of Consumer Research Inc. 
Russell, C.A., Stern, B.B. (2006). Consumer's, Characters and Products: A Balance Model of Sitcom Product Placement Effects. Journal of Advertising, 35(1), 7-21. Retrieved from M. E. Sharpe Inc.

Schemer, C., Matthes, J., Wirth, W., Textor, S. (2008). Does "Passing the Courvoisier" always pay off? Positive and Negative Evaluative Conditioning Effects of Brand Placements in Music Videos. Psychology and Marketing, 25(10), 923-943. DOI: 10.1002/mar.20246

Schiffman, L. G., Kanuk, L. L. (2009). Consumer Behavior (10 th ed.). Pearson Prentice Hall.

Statistics South Africa. (2011). National Census 2011. Retrieved from http://mobi.statssa.gov.za/census/Internet.html

Van Der Waldt D.L.R., Du Preez, L.D., Williams, S. (2008a). Recognition and Recall of Product Placements in Films and Broadcast Programmes. Innovar, 18(31), 19-28. Retrieved from the institutional repository of University of Pretoria.

Van Der Waldt D.L.R., Du Preez, L.D., Williams, S. (2008a). Recognition and Recall of Product Placements in Films and Broadcast Programmes. Innovar, 18(31), 19-28. Retrieved from the institutional repository of University of Pretoria.

Van Der Waldt, D.L.R. (2005). The Role of product Placement in Feature Films and Broadcast Television Programmes: an IMC Perspective. Communicare, 24(2), 1-16. Retrieved from the institutional repository of the University of Pretoria

Van Der Waldt, D.L.R., Du Preez, L.D., Williams, S. (2007a). Gender Differences on Ethically Charged Product Placements: The Case of Tobacco Products, Alcoholic Beverages and Weapons. Commercium, 8(1), 33-45. Retrieved from the institutional repository of University of Pretoria.

Van Der Waldt, D.L.R., Du Preez, L.D., Williams, S. (2007a). Gender Differences on Ethically Charged Product Placements: The Case of Tobacco Products, Alcoholic Beverages and Weapons. Commercium, 8(1), 33-45. Retrieved from the institutional repository of University of Pretoria.

Van Der Waldt, D.L.R., Du Toit, L.S., Redelinghuys, R. (2007b). Does Branded product Placement Enhance Realism and Brand Recognition by Consumers? African Journal of Business Management pp, 19-25. Retrieved from the institutional repository of the University of Pretoria.

Van Der Waldt, D.L.R., Nunes, V., Stroebel, J. (2008b). Product Placement: Exploring the effects of Product Usage by Principal Actors. African Journal of Business Management, 2(6), 111-118. Retrieved from the institutional repository of the University of Pretoria.

Van Der Waldt, D.L.R., Nunes, V., Stroebel, J. (2008b). Product Placement: Exploring the effects of Product Usage by Principal Actors. African Journal of Business Management, 2(6), 111-118. Retrieved from the institutional repository of the University of Pretoria. 